\title{
Microbial infection, inflammation and epithelial ovarian cancer (Review)
}

\author{
XIAOHUI XIE, MENGYUAN YANG, YILING DING and JIANLIN CHEN \\ Department of Obstetrics and Gynecology, The Second Xiangya Hospital of Central South University, \\ Changsha, Hunan 410001, P.R. China
}

Received November 3, 2015; Accepted April 13, 2017

DOI: $10.3892 / 01.2017 .6388$

\begin{abstract}
Ovarian cancer is the most common, and life-threatening, type of female gynecological cancer. The etiology of ovarian cancer remains unclear, and there are currently no effective screening or treatment methods for the disease. Microbial infection serves a marked function in inducing carcinogenesis. A number of studies have identified pelvic inflammatory disease as a risk factor for epithelial ovarian cancer. Thus, it is hypothesized that microbial infection may contribute to ovarian cancer. In the present review, the microorganisms that have been identified to be associated with ovarian cancer and the underlying molecular mechanisms involved are discussed. Infection-induced chronic inflammation is considered an important process for carcinogenesis, cancer progression and metastasis. Therefore, the pathological process and associated inflammatory factors are reviewed in the present paper.
\end{abstract}

\section{Contents}

1. Introduction

2. Ovarian carcinogenesis and microorganisms

3. Inflammation and ovarian carcinogenesis

4. Conclusions

\section{Introduction}

Ovarian cancer is the most life-threatening type of gynecological cancer in females. According to Cancer Statistics (1), there were an estimated 22,440 novel cases of ovarian cancer in 2017. In addition, the number of ovarian cancer-associated

Correspondence to: Dr Mengyuan Yang, Department of Obstetrics and Gynecology, The Second Xiangya Hospital of Central South University, Surgery Building A, Renmin Zhong Road, Changsha, Hunan 410001, P.R. China

E-mail: mengyuanyang_csu@sohu.com

Key words: microbial infection, inflammation, epithelial ovarian cancer, angiogenesis, endothelial mesenchymal transition, cancer stem cell, cancer-associated fibroblasts mortalities was 14,080 , which was the fifth most common cause of cancer-associated mortality in American females (1). Epithelial ovarian cancer (EOC) is the most common histological type of ovarian cancer, with $\sim 75 \%$ cases of ovarian cancer diagnosed at an advanced stage (FIGO stages III-IV) and the overall survival rate of EOC ranging between 15 and $30 \%$ for the last 20 years (2). The exact cause of ovarian cancer remains unclear; however, a number of associated risk factors have been identified. Ovulation-associated factors including pregnancy frequency, breastfeeding, early menarche, late menopause and the use of the oral contraceptive pill were all associated with EOC. In addition, hereditary factors served an important function in the development of ovarian cancer, with females who had a family history of ovarian cancer, personal history of breast cancer or alteration in breast cancer early onset (BRCA)1 or BRCA2 genes contributed to an increased risk of EOC. Furthermore, inflammation was a risk factor of EOC, and females who have experienced pelvic inflammatory disease (PID), endometriosis or frequent exposure to talc and asbestos were identified to exhibit an increased risk of ovarian cancer (3). Lin et al identified that females with an episode of clinically apparent PID exhibited a 1.9-fold increase in the development of EOC, whereas females who had experienced $\geq 5$ episodes of PID exhibited a 2.5-fold increased risk. In addition, patients with PID aged $\leq 35$ years were at an increased risk of developing ovarian cancer compared with the control population during 1-3 years of follow-up (4). In early 1995, a case-control study, including 450 females with ovarian cancer and 564 controls, revealed that $23.1 \%$ of cases and $18.1 \%$ of controls had PID and, adjusted for age, smoking, country of birth, parity, duration of oral contraceptive use and abortion, the odds ratio was 1.53 [95\% confidence interval (CI), 1.10-2.13; $\mathrm{P}=0.012$ ] (5). Furthermore, females with recurrent PID presented an increased risk (odds ratio, 1.88; 95\% CI, 1.13-3.12; $\mathrm{P}=0.014)$, which suggested that PID may increase the risk of developing ovarian cancer (5). In a Chinese study conducted in 1989, PID was associated with an increased risk of inducing ovarian cancer (odds ratio, 3.0; 95\% CI, 0.30-30.2) (6).

Malignancies are hypothesized to be partially initiated by microbial infections and $>15 \%$ of malignancies may be attributed to infections (7). According to the International Agency for Research on Cancer (IARC), 6 viruses and 1 bacterium are certified as causes of cancer, which are human papillomavirus 
(HPV), hepatitis B virus (HBV), hepatitis C virus (HCV), Epstein-Barr virus (EBV), human T-lymphotropic virus 1 and Kaposi's sarcoma-associated herpes virus, and Helicobacter pylori, respectively. Persistent infections induce chronic inflammation which may cause successive inflammatory reactions, thus dysregulated innate or adaptive immune responses may be pro-tumorigenic (8). In the present review, studies of microorganisms that may induce ovarian carcinogenesis are summarized and the underlying molecular mechanisms that link chronic inflammation to ovarian cancer are examined.

\section{Ovarian carcinogenesis and microorganisms}

Chlamydia trachomatis. C. trachomatis is one of the most common types of bacteria that cause sexually transmitted infections (STIs). In the USA, almost 4 million cases of C. trachomatis infections occur each year; however, only $25 \%$ of those cases were diagnosed and treated (9). C. trachomatis an obligate intracellular bacterium with a unique life cycle involving stages of infective extracellular elementary body (EB) and non-infective intracellular reticulate body (RB) (10). Unlike the majority of bacteria, C. trachomatis intracellular and, unlike viruses, $C$. trachomatis possesses DNA and RNA (11). When a host is infected with $C$. trachomatis, the host exhibits a long asymptomatic period, since the host immune response fails to control infection. According to Molano et al (12), 46, 18 and 6\% of C. trachomatis infections were persistent for 1,2 and 4 years of follow-up, respectively, as determined using plasmid polymerase chain reaction, without consideration of serotypes. After 4 years of follow-up, $94 \%$ of females who had a $C$. trachomatis infection were healthy (13). During a period of infection, the innate and adaptive immune system are stimulated to fight against infection. The innate immune system initiates more rapid and primitive responses to infection, compared with that of the adaptive immune system, and includes surface defenses, cytokine elaboration, complement activation and phagocytic responses (14). The innate immune response begins by the binding of pathogen-associated molecular patterns (PAMPs) to cell receptors, activating nuclear factor- $\kappa \mathrm{B}(\mathrm{NF}-\kappa \mathrm{B})$ which subsequently binds to specific DNA sequences in the nucleus, inducing the production of pro-inflammatory cytokines $(14,15)$. In addition, the natural antimicrobial peptides (NAPs) and pattern recognition Toll-like receptors (TLRs) are key mediators of the innate immune system. Secretory leukocyte protease inhibitor (SLPI) and elafin are potential NAPs; an oviductal epithelial cell line infected with $C$. trachomatis increased the expression level of elafin (16). TLRs are typically expressed in epithelial cells; previous studies have identified that Chlamydia activated TLR3 in murine reproductive tract epithelial cells and TLR2 is critical for Chlamydia-mediated host cell activation and pathology $(17,18)$. The host immune system-stimulated production of pro- or anti-inflammatory cytokines are considered to be important factors in determining the disease outcomes. For instance, interferon (IFN)- $\gamma$, interleukin (IL)-6, IL-8, IL-10, IL-12, neutrophils or macrophages serve protective or destructive roles in C. trachomatis infection, PID or infertility (19). Persistent inflammation and the subsequent tissue damage or inhibition of apoptosis of host cells contribute to carcinogenesis following Chlamydia infection (20). According to Shanmughapriya et al (21), $80 \%$ of ovarian cancer cases were identified as positive for Chlamydia; however, none of the controls were determined to be positive. Additionally, a previous seroepidemiological study identified a positive association between plasma $C$. trachomatis immunoglobulin (Ig)G and ovarian tumors (22). Owing to the hypothesis of the tubal origin of epithelial ovarian cancer, Carvalho and Carvalho (23) identified that primary tubal cancer, induced by C. trachomatis fimbrial infection, may be an origin of serous ovarian carcinoma; however, additional study was required. Acute $C$.trachomatis infection activated the paracrine Wnt signaling pathway, which led to profound disruption of the fallopian tube epithelial structure and function that facilitated the dissemination of damage beyond that of infected cells (24). Furthermore, heat shock protein 60 (HSP60) is an immune protein that induces immune responses. HSP60, synthesized during $C$. trachomatis infection, is markedly conserved in evolution and possesses common antigenic epitopes (25). Exogenous HSP60 from microbes may stimulate the immune response in humans and additionally reacts with the endogenous chaperonin (26). The accumulation of exogenous chlamydial HSP60 in the cytoplasm of active replicating eukaryotic cells may interfere with the regulation of the apoptotic pathway (27). In addition, overexpression of HSP60 induced tumor viability and metastasis $(28,29)$. Furthermore, the concentrations of IgG antibodies against HSP60/65 was increased in ovarian cancer serum, compared with the controls, and HSP60 expression in ovarian cancer tissues was visibly increased compared with normal ovarian tissues $(30,31)$.

Mycoplasma genitalium. M. genitalium is a microbe that causes STIs in males and females, and it is $>30$ years since it was initially isolated from males with non-gonococcal urethritis (32). M. genitalium belongs to the mollicutes class and is the smallest self-replicating organism consisting of $580 \mathrm{~kb}$ and 485 genes $(33,34)$. The prevalence rate of M. genitalium in females is decreased compared with that of $C$. trachomatis. According to Manhart et al (35), the genital prevalence rates of M. genitalium, Neisseria gonorrhoeae and C. trachomatis were $\sim 1,0.4$ and $4.2 \%$, respectively. Infection of M. genitalium was associated with non-gonococcal urethritis, bacterial vaginosis and vaginitis, cervicitis, PID and infertility in females (36). The role served by $M$. genitaliumin ovarian cancer is controversial. According to Idahl et al (22), serum M. genitalium $\mathrm{IgG}$ antibodies were markedly increased in ovarian malignancies or benign tumors compared with that in controls. However, in another study, M. genitalium was not identified in ovarian tumor tissues (37). According to Chan et al (38), mycoplasmas were detected in $59.3 \%$ of the malignant ovarian cancer specimens. In contrast, Quirk et al (39) identified Mycoplasma DNA in only $6(13 \%)$ of the 46 ovarian tumor DNA samples, which failed to determine an association between ovarian cancer and Mycoplasma.M. genitalium was positive in a number of additional types of malignancy, BPH-1 cells, after 19 weeks of co-culture with $M$. genitalium, exhibited anchorage-independent viability and the migration and invasion ability was markedly increased; the infected BPH-1 cells were also found to be tumorigenic in nude mice (40). In addition, cervical, vaginal and prostatic epithelial cells secreted a number of inflammatory cytokines following infection with M. genitalium including IL-6 and 


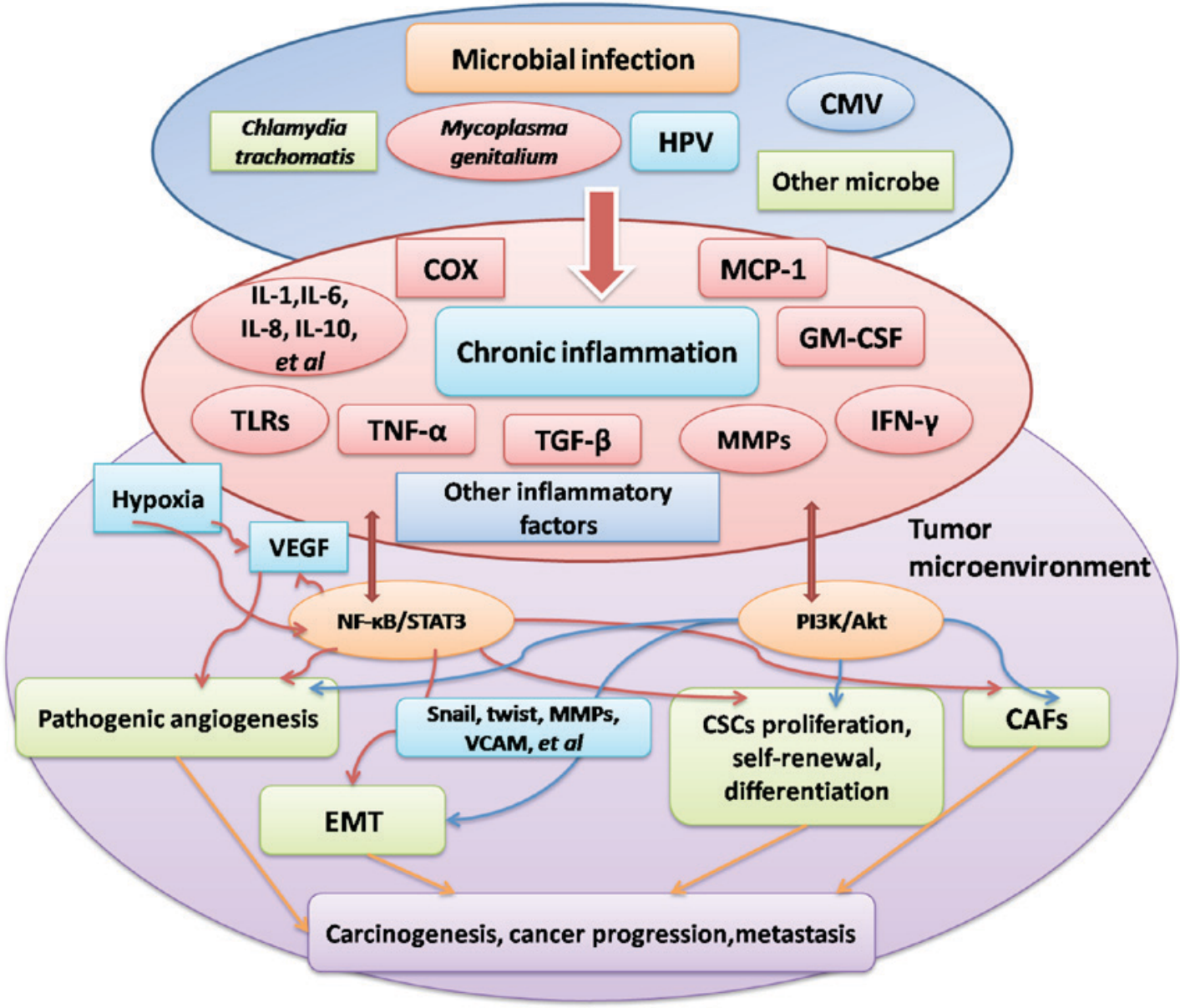

Figure 1. Inflammatory factors and signaling pathways in cancer induced by microbial infection. CMV, cytomegalovirus; HPV, human papillomavirus; COX, cyclooxygenase; MCP-1, monocyte chemotactic protein 1; GM-CSF, granulocyte/macrophage colony-stimulating factor; IL, interleukin; TLR, Toll-like receptor; TNF- $\alpha$, tumor necrosis factor $\alpha$; MMP, matrix metalloproteinase; IFN- $\gamma$, interferon- $\gamma$; VEGF, vascular endothelial growth factor; NF- $\mathrm{B}$, nuclear factor-kB; STAT3, signal transducer and activator of transcription 3; PI3K, phosphoinositide 3-kinase; Akt, protein kinase B; Twist, Twist-related protein 1; VCAM, vascular cell adhesion protein; EMT, epithelial-mesenchymal transition; CSC, cancer stem cell; CAF, cancer-associated fibroblast.

IL-8 (41,42). Furthermore, Mycoplasma infection served an oncogenic function in cultured mouse embryo cells (43). The pathophysiology process of $M$. genitalium infection included adherence to epithelial cells, cell invasion, production of toxins and immunological responses (36). These processes were associated with PID and tubal factor infertility. M. genitalium infection traversed from the lower genital tract to upper genital tract, which caused persistent inflammation in the fallopian tubes and ovaries (44). According to Baczynska et al (45) and Crum et al (46), M. genitalium and Mycoplasma hominis caused swelling of the tubal epithelial cilia, through production of a toxin or metabolism products, which was consistent with previous studies that ovarian cancer originated from the fallopian tube epithelium. As aforementioned, the immunological response serves an essential function in $M$. genitalium infection. Persistent $M$. genitalium infection enhanced endocervical epithelial cells secretion of IL-6, IL-8, granulocyte colony-stimulating factor, granulocyte/macrophage colony-stimulating factor (GM-CSF) and monocyte chemotactic protein (MCP)-1, and increased the sensitivity to TLR agonists. This suggested that infected subjects may be hyper-responsive to exogenous innate immune stimulation induced by STIs, or to other STIs including bacterial vaginosis (47). Furthermore, a previous study demonstrated that following inoculation with $M$. genitalium of 3D endocervical epithelial cells for $48 \mathrm{~h}$, host defense and inflammation-associated genes were activated (48). Pro-inflammatory cytokines including IL-6, IL-7, IL-8, MCP-1 and GM-CSF were secreted following $M$. genitalium infection (48).

Human papillomavirus (HPV). HPV is one of the most common types of sexually transmitted virus in the world. In the USA, the overall HPV prevalence was $26.8 \%$ in females aged between 14 and 59 years; however, in females aged between 20 and 24 years, the HPV prevalence rate was $\leq 44.8 \%$ (49). In China, a pooled analysis of 17 population-based studies, including 30,207 females, identified the HPV prevalence to be $17.7 \%$ (50). Furthermore, a province-wide study was conducted in Ningbo province which identified 185 of 1,373 females aged between 22 and 64 years (13.5\%) as HPV-positive and the prevalence rates were $13.8,8.8$ and $7.9 \%$ in Shenzhen, Xinjiang and Chaozhou, respectively (51-54). The papillomavirus family is heterogeneous and highly species-specific. Over 200 HPV genotypes have been identified and these are subdivided into three broad categories, depending on their oncogenic potential. High-risk HPV types include HPV-16, HPV-18, HPV-31, HPV-33, HPV-35, HPV-45, HPV-51, HPV-52, HPV-56, HPV-58, HPV-59, HPV-68 andHPV-73. HPV-16 
and HPV-18 are the most common types of HPV identified in malignancies (55). In addition, HPV was demonstrated to be positive in a number of types of malignancy. According to Tang et al (56), HPV was detected in $96.6 \%$ of cervical carcinomas, in $14.1 \%$ of head and neck squamous cell carcinomas, and in bladder urothelial carcinoma and lung squamous cell carcinoma. Whether HPV infection, $C$. trachomatis or $M$. genitalium are associated with ovarian cancer is debated. A previous meta-analysis, summarizing 24 primary studies from 11 countries on 3 continents, contained information on HPV and ovarian cancer and included 880 subjects (57). This study identified an association between HPV infection and ovarian cancer, as HPV prevalence in patients with ovarian cancer was demonstrated to be $17.5 \%$. In Saudi patients, an increased proportion of HPV-16 and HPV-18 was observed in 42.9 and $26.2 \%$ ovarian cancer tissues, respectively (58). In addition, previous studies identified that increased-risk HPV DNA may be determined in ovarian serous carcinomas and present in females at a high risk of developing EOC (including females with $\geq 2$ first-degree relatives with ovarian or breast cancer or females with mutations in BRCA1 or BRCA2 genes) $(59,60)$. However, a study from Iraq identified that HPV-16 existed in only $9.67 \%$ of malignant ovarian epithelial tumors, which suggested that HPV infection served a relatively minor function in the pathogenesis of ovarian cancer (61).

HPV replicates and assembles exclusively in the nucleus, and initially establishes infection in undifferentiated and actively proliferating cells in the basal layer of epithelium cells. During carcinogenic progression, the HPV genome typically integrates into a host cell chromosome, and the viral oncoproteins E6 and E7 induce cell immortalization and transformation (62). E6 and E7 inactivate two cellular tumor suppressor proteins: p53 and retinoblastoma protein (63). HPV-16 E7 increased the retention of $\gamma-\mathrm{H} 2 \mathrm{~A}$ histone family, member X (a marker for cellular response to DNA damage) and decreased sublethal DNA damage repair in head and neck cancer cells. The results of this study suggested that E7 expression markedly delayed radiation-induced DNA damage repair in head and neck normal epithelial cells, and head and neck cancer cells (64). In addition, HPV E6/E7 were identified to increase the intracellular expression of the oncogenic microRNA 17-92 cluster and decrease the expression of the anti-proliferative p21 gene in HPV-positive cancer cells (65). According to Gregoire et al (66), introduction of HPV-16 E6/E7 genes into human ovarian surface epithelial (HOSE) cells may extend the lifespan and induce malignant transformation of these cells.

Cytomegalovirus (CMV). CMV infection is rarely associated with ovarian cancer. Shanmughapriya et al (21) identified $\sim 50 \%$ of ovarian cancers to be CMV-positive, of which 80 and $20 \%$ were invasive and borderline tumors, respectively. As discussed in a review (67), 10 studies have described CMV oophoritis, which demonstrated that CMV infection may cause an underlying malignancy or immunosuppressive status. In addition, the aforementioned review identified steroid therapy as a strong risk factor for CMV reactivation (67). Furthermore, CMV infection was revealed to contribute to a number of types of malignancy including those of brain, breast, colon, cervical andprostate (68-72). CMV is not a typical oncogenic virus, but it is described as an oncomodulation virus (73). CMV proteins may control the cell cycle, inhibit apoptosis and induce telomerase activity, angiogenesis and cellular migration (74). A previous study identified that human HCMV binds to epithelial growth factor receptor and integrins $\alpha v \beta 3$ and $\alpha 2 \beta 1$ to induce an angiogenic response to human mammary epithelial cells (75). CMV IL-10 is an HCMV UL111A gene product that has $27 \%$ sequence identity with IL-10; CMV IL-10 could bind the IL-10 receptor expressed by MCF-7 breast cancer cells to promote proliferation of MCF-7 cells (76). In addition, mouse CMV infection was identified to enhance glioblastoma cell viability through signal transducer and activator of transcription STAT3 activation, whereas the STAT3 inhibitor prevented the HCMV stimulation in human glioblastoma neurosphere growth (in vitro and in vivo) (77).

\section{Inflammation and ovarian carcinogenesis}

Inflammation is a biological response to disrupted tissue homeostasis and possesses four essential factors including inducers, sensors, inflammatory mediators and target tissues (78). Microbial infection is one of the most common types of inducer which promotes inflammatory responses; other inducers include autoimmune diseases and agnogenic inflammatory diseases (79). Inflammatory sensors include macrophages, dendritic cells, mast cells, T cells, B cells, fibrocytes and endothelial cells. Inflammation is mediated by immune cells as an immediate defense in response to infection or injury by noxious stimuli. Innate immune cells, including neutrophils, mast cells and macrophages, exhibit receptors that signal the activation and production of an array of biologically active proteins and defense molecules, in response to detrimental substances and damaged or altered self-molecules (80). Inflammatory mediators including inflammatory cytokines, chemokines, growth factors, reactive oxygen and nitrogen species and cytokines, secreted by inflammatory cells, cause genomic alterations in the epithelium and subsequent cancer initiation. Chronic infections are responsible for $15 \%$ of malignancies worldwide $(81,82)$. For example, GM-CSF/IFN- $\gamma$-and GM-CSF/IL-3/IFN- $\gamma$-deficient mice were administered with acute and chronic inflammatory reactions in a number of organs, particularly in the lungs, soft tissues, lymph nodes, ovaries, adrenal glands and the liver. A previous study indicated that the cause of cancer formation in these mice was bacterial, presumably due to the creation of a persistent inflammatory response (83). There have been notable studies which identified that factors associated with immune responses may alter the pathogenesis and initiation of ovarian cancer, through genetic and protein analysis (84). According to Curiel et al (85), regulatory $\mathrm{T}$ (Treg) cells served a substantial role in ovarian cancers, and blocking Treg cell migration or function may aid ovarian cancer therapy. Furthermore, Treg cells were associated with an increased risk of mortality and decreased survival time. C-C motif chemokine 22, produced by the tumor microenvironment, was suggested to be a mediator of Treg cells and tumors (85). According to Block et al (86), pro-inflammatory factor NF- $\mathrm{kB}$-associated single-nucleotide polymorphisms were associated with the overall survival time of patients with ovarian cancer. A case-control study, including 7,776 cases and 11,843 controls, revealed that regular use of non-steroidal anti-inflammatory drugs, including aspirin, decreased the risk of ovarian cancer (87). 
Inflammation-activated angiogenesis and carcinogenesis. Inflammation-induced angiogenesis is associated with a number of pathophysiological processes including tumor viability, wound healing and ovulation. The process of angiogenesis is regulated by angiogenic cytokines and grow th factors secreted by inflammatory cells. Inflammation and hypoxia are two primary types of angiogenesis inducers. Vascular endothelial growth factor (VEGF), induced by chronic inflammation, serves functions in tumor angiogenesis, viability and metastasis, and targeting VEGF to inhibit angiogenesis may prevent cancer progression $(88,89)$. The $N F-\kappa B$ pathway, critical for pro-inflammatory gene expression, is considered to exhibit a function in angiogenesis of tumor and inflamed tissues, and the $\mathrm{NF}-\kappa \mathrm{B}$-inducing kinase may be a therapeutic target in chronic inflammatory diseases and tumor neoangiogenesis (90). Hypoxia, when tissues lack oxygen, induces angiogenesis and inflammation, and hypoxia-inducible factor (HIF)-1 activation is well-known as an adaptive strategy to hypoxia and consists of two subunits: HIF-1 $\alpha$ and HIF-1 $\beta$. HIF-1 activates transcription of genes encoding angiogenic growth factors, including VEGF, angiopoietin (ANGPT)1, ANGPT2 and platelet-derived growth factor, which are secreted by hypoxic cells and stimulate epithelial cells, resulting in angiogenesis (91). Angiogenesis has been identified as a necessary process for oncogenesis and subsequent tumor growth. Exosomes, extracted from high-grade ovarian cancer cells, induce angiogenesis, and activating transcription factor 2 and metastasis-associated 1 may serve a key function in exosomal enhancement of tumor development (92). In addition, angiogenesis is associated with the formation of malignant ascites in ovarian cancer (93). Anti-angiogenesis therapy is regarded as a novel effective therapeutic strategy for ovarian cancer and a number of clinical trials have validated angiogenesis as a target in ovarian cancer, through the addition of VEGF pathway inhibitors, including the monoclonal anti-VEGF antibody bevacizumab. A previous meta-analysis, including 12 studies, demonstrated that the incorporation of anti-angiogenesis therapy was markedly associated with an improved clinical outcome (94,95). Microbial infection which induces angiogenesis serves a vital function in tumorigenesis. According to Li et al (96), lung cancer cells which overexpress HPV-16 E6 and E7 oncoproteins markedly stimulate capillary tube formation of human umbilical vein endothelial cells in vitro and increase tumor angiogenesis, HIF- $1 \alpha$ and VEGF proteins in vitro and in vivo. HCMV infection is present in $>90 \%$ of glioblastoma multiforme (GBM) and HCMV viral protein pp71 induced the production of stem cell factor (SCF), an important pro-angiogenic factor in GBM. Furthermore, the secretion of SCF stimulated by pp71 requires the activation of the NF- $\kappa \mathrm{B}$ signaling pathway (97).

Inflammation-activated epithelial-mesenchymal transition and carcinogenesis. Epithelial-mesenchymal transition (EMT) is a biological process where epithelial cells lose their planar and apical-basal polarity and cell-cell adhesion, and gain migratory and invasive properties to become mesenchymal stem cells. EMT was first recognized as a feature of embryogenesis and it additionally occurs in wound healing, organ fibrosis, cancer progression and cancer metastasis (98). EMT is characterized primarily by the loss of epithelial
(E-)cadherin and a number of transcription factors have been identified to repress E-cadherin. Zinc finger protein SNAI1 (Snail), zinc finger E-box-binding homeobox (ZEB), E2A immunoglobulin-enhancer binding factor (E47) and Krüppel-like factor 8 bound to and repressed the activity of the E-cadherin promoter; whereas Twist-related protein 1 (Twist) and FOXC2 were common factors that repressed E-cadherin transcription indirectly. Furthermore, a previous study demonstrated that EMT was utilized by cancer cells to enhance aggressiveness by acquiring chemoresistance and stem-cell-like properties and escaping from host immunity (99). Snail was upregulated in ovarian cancer and was identified to be positively associated with the expression of fibronectin and neuralcadherin, but was negatively associated with the expression of E-cadherin and $\beta$-catenin (100). Oncogene high-mobility group AT-Hook 2 was revealed to be a EMT-associated gene that was overexpressed in OSE cell lines and assisted in the understanding of the tumorigenesis of ovarian serous carcinoma (101). In addition, EMT is associated with ovarian cancer which is resistant to conventional chemotherapy. A previous study identified EMT genes, including Snail, zinc finger protein SNAI2 (Slug), Twist2 and Zeb2, upregulated in cisplatin-resistant ovarian cancer cell lines; however, following knockdown of the Snail and Slug genes, the EMT phenotype was reversed and drug sensitivity was restored (102). Inflammatory factors tumor necrosis factor- $\alpha$, transforming growth factor (TGF)- $\beta 1$ and IL-6 induced EMT in inflammatory breast cancer cells, through the NF- $\kappa \mathrm{B}$ and STAT3 signaling pathways (103). Microbes including Helicobacter, Mycoplasma hyorhinis, Citrobacter rodentium, EBV and HCV were reported to induce EMT (104-108). The components and products of bacteria are considered to serve functions in the induction of EMT. Li et al (109) identified that lipopolysaccharide (LPS) promoted invasion and metastasis of liver hepatocellular carcinoma HepG2 cells and downregulated the expression of E-cadherin, suggesting that TLR4 may involve the process of EMT. Furthermore, LPS was demonstrated to decrease E-cadherin expression in intrahepatic biliary epithelial cells (HIBEpiCs) and increased the mesenchymal markers S100 calcium-binding protein A1 and sterile $\alpha$ motif. In addition, it was hypothesized that LPS induced EMT of HIBEpiCs, through the TGF- $\beta 1 / \mathrm{Smad} 2 / 3$ signaling pathway (110). Flagellin and muramyl dipeptides are two bacterial products that maybe associated with EMT. A previous study revealed that flagellin induced EMT by activating $\mathrm{NF}-\kappa \mathrm{B}$ and mitogen-activated protein kinase (MAPK), but failed to increase the level of Snail in A549 adenocarcinomic human alveolar basal epithelial cells and BEAS-2B human bronchial epithelial cells (111). Muramyl dipeptides were considered to activate nucleotide-binding oligomerization domain-like receptors (NOD) and subsequently recruit receptor-interacting serine/threonine kinase 2, a kinase required for NOD-mediated NF- $\kappa \mathrm{B}$ and MAPK activation (112). A previous study revealed that EBV induced EMT of human corneal epithelial cells through activation of phosphoinositide 3-kinase (PI3K)/protein kinase B (Akt) and extracellular-signal-regulated kinase (ERK) signaling pathways (113). The EBV latent membrane protein 1 (LMP1) and 2A (LMP2A) are involved in EMT; it was first identified that LMP1 induced EMT via Twist in nasopharyngeal carcinoma 
tissues. Furthermore, LMP1 in lung epithelium predisposed cells to undergo EMT by enhancing signaling through the ERK signaling pathway and the interaction with TGF- $\beta 1$ may also stimulate EMT $(114,115)$. In addition, $\mathrm{HCV}$ induces EMT: HCV core protein repressed E-cadherin expression by upregulating E12/E47 to induce EMT. In cholangiocarcinoma, HCV has been shown to induce EMT, promoting carcinoma progression through a mechanism dependent on the lysyloxidase-like 2 signaling pathway (116).

Inflammation-activated cancer stem cells (CSCS) and carcinogenesis. CSCs are defined as cells that possess the capacity of self-renewal, cancer viability, metastasis, recurrence and they are not sensitive to radio- and chemotherapy. CSCs exist in a number of types of cancer, including ovarian, breast, colon, prostate and leukemia. Bapat et al (117) were the first to isolate ovarian CSCs from ascites of patients with ovarian cancer, 19 of which were spontaneously immortalized and two cell lines were characterized with CSCs that presented the specific markers of stem cells including Nestin, octamer-binding transcription factor 4 and Nanog. Additional biomarkers of ovarian CSCs include aldehyde dehydrogenases, cluster of differentiation (CD)44, CD133, CD24, epithelial cell adhesion molecule, CD117, lymphocyte antigen 6 complex, locus $\mathrm{A}$ and leucine-rich repeat-containing G-protein-coupled receptor 5 (118). CSCs interact with, and are regulated by, a number of signaling pathways and cytokines inthe tumor microenvironment. Inflammatory cytokines, including IL-1, IL-6 and IL-8, activate the STAT3/NF-kB signaling pathway in tumor and stromal cells, which stimulates cytokine production and self-renewal of CSCs. The positive-feedback loops contribute to the interactions between chronic inflammation and cancer (119). NF- $\mathrm{\kappa B}$ is a primary source of pro-inflammatory cytokines and a previous study demonstrated that NF- $\mathrm{KB}$ inhibitors may induce cell death in ovarian CSCs, which prevented cancer recurrence and chemoresistance (120). In addition, TLRs that respond to PAMPs served an important function in EOC stem cells and TLR2, TLR4, TLR5 and TLR9 recognize primarily bacterial products, whereas TLR3 and TLR8 recognize viral components. A previous study identified the TLR2-myeloid differentiation primary response gene 88 (MyD88)-NF- $\mathrm{kB}$ signaling pathway as being able to promote tumor repair and enhance self-renewal in $\mathrm{CD} 44^{+} / \mathrm{MyD} 88^{+}$ EOC stem cells (121). IL-17, secreted by Thelper 17 cells and macrophages in the tumor microenvironment, binds to IL-17 receptor, overexpressed in ovarian $\mathrm{CD} 133^{+}$cancer stem-like cells, and subsequently increased the tumorigenic potential and self-renewal, through the NF- $\mathrm{kB}$ and $\mathrm{p} 38$ MAPK signaling pathway in vitro and in vivo (122). Cell viability of ovarian cancer cells was markedly increased following co-culture with carcinoma-associated mesenchymal stem cells (CA-MSCs), which existed in the tumor microenvironment and protected ovarian cancer cells from carboplatin-induced viability inhibition and apoptosis. Furthermore, phosphorylation of Akt and $\mathrm{X}$-linked inhibitor of apoptosis protein served an important function in stimulating CA-MSC-secreted factors which protect ovarian cancers from carboplatin-induced apoptosis (123).

Inflammation-activated cancer-associated fibroblasts and carcinogenesis. The tumor microenvironment is composed of distinct cellular and structural factors, including the vasculature, immune-associated cells, fibroblasts and extracellular matrix. Cancer-associated fibroblasts (CAFs) exhibit a function in tumor-stroma crosstalk. Fibroblasts are involved in tissue repair, the inflammatory response, human tumorigenesis and metastasis. EBV infection was suggested to induce myofibroblast activation in scleroderma (SSc) fibroblasts and the profibroblast-associated factors, including TGF- $\beta 1$, endothelin 1, SMA as well as TGF $\beta$-regulated genes such as early growth response 1, plasminogen activator inhibitor-1, cartilage oligomeric matrix protein and basement membrane-zone genes coding for collagen IV, were up-regulated in SSc fibroblasts (124). LPS of bacteria directly induces lung fibroblast viability by activating TLR4 signaling, and TLR4-induced activation of the PI3K-Aktsignaling pathway and downregulation of phosphatase and tensin homolog served a function in the process (125). In ovarian cancer, CAFs upregulated the expression of the pro-inflammatory factors IL-6, cyclooxygenase-2 and the chemokine (C-X-C motif) ligand 1. Furthermore, NF- $\kappa \mathrm{B}$ expression was enhanced by CAFs, which suggested that pro-tumorigenic signaling in the microenvironment of ovarian tumors via the NF- $\mathrm{kB}$ signaling pathway was mediated partly by CAFs (126). TGF- $\beta$ is a fibrosis-associated cytokine that serves a significant function in cancer invasion and metastasis. Ovarian cancer cells exhibited increased motility when co-cultured with fibroblasts in the presence of exogenous of TGF- $\beta 1$ and TGF- $\beta 2$, suggesting that TGF- $\beta$ modulated molecular crosstalk between ovarian cancer cells and CAFs in ovarian cancer microenvironment (127). In addition, CAFs may facilitate the invasiveness of originally non-invasive cancer cells, through protease-activated receptor-dependent $\mathrm{Ca}^{2+}$ signals and matrix metalloproteinase-1 upregulation (Fig. 1) $(128,129)$.

\section{Conclusions}

Chronic inflammation serves an important function in stimulating tumorigenesis. A number of large case-control studies have identified an association between PID and ovarian cancer (4-6). Microorganisms including C. trachomatis, M. genitalium, HPV and CMV have been identified to induce ovarian cancer and other types of malignancy. In addition, angiogenesis, EMT, CSCs and CAFs are important factors that lead to ovarian cancer progression, viability and metastasis, and may be stimulated by microbial infection. Furthermore, the four processes are essential for the interaction between inflammation and the tumor microenvironment. The pathogenesis of inflammation-associated cancer remains unclear and a limited number of therapeutic methods are currently used to treat cancer. Therefore, the present review aimed at describing the function of microbial infection in inducing ovarian cancer and in the tumor microenvironment, and to assist the development of novel strategies to prevent and treat ovarian cancer.

\section{References}

1. Siegel RL, Miller KD and Jemal A: Cancer Statistics, 2017. CA Cancer J Clin 67: 7-30, 2017.

2. Herzog TJ and Pothuri B: Ovarian cancer: A focus on management of recurrent disease. Nat Clin Pract Oncol 3: 604-611, 2006

3. Hunn J and Rodriguez GC: Ovarian cancer: Etiology, risk factors, and epidemiology. Clin Obstet Gynecol 55: 3-23, 2012. 
4. Lin HW, Tu YY, Lin SY, Su WJ, Lin WL, Lin WZ, Wu SC and Lai YL: Risk of ovarian cancer in women with pelvic inflammatory disease: A population-based study. Lancet Oncol 12: 900-904, 2011.

5. Risch HA and Howe GR: Pelvic inflammatory disease and the risk of epithelial ovarian cancer. Cancer Epidemiol Biomarkers Prev 4: 447-451, 1995.

6. Shu XO, Brinton LA, Gao YT and Yuan JM: Population-based case-control study of ovarian cancer in Shanghai. Cancer Res 49: 3670-3674, 1989.

7. Kuper H, Adami HO and Trichopoulos D: Infections as a major preventable cause of human cancer. J Intern Med 248: 171-183, 2000.

8. Garrett WS: Cancer and the microbiota. Science 348: 80-86, 2015.

9. Centers for Disease Control and Prevention1, Workowski KA and Berman SM: Sexually transmitted diseases treatment guidelines, 2006. MMWR Recomm Rep 55: 1-94, 2006.

10. Ladany S and I Sarov: Recent advances in chlamydia trachomatis. Eur J Epidemiol 1: 235-256, 1985.

11. Moulder JW: Interaction of chlamydiae and host cells in vitro. Microbiol Rev 55: 143-190, 1991.

12. Molano M, Meijer CJ, Weiderpass E, Arslan A, Posso H, Franceschi S, Ronderos M, Muñoz N and van den Brule AJ: The natural course of Chlamydia trachomatis infection in asymptomatic Colombian women: A 5-year follow-up study. J Infect Dis 191: 907-916, 2005.

13. Tosi MF: Innate immune responses to infection. J Allergy Clin Immunol 116: 241-249; quiz 250, 2005.

14. den Hartog JE, Morré SA and Land JA: Chlamydia trachomatis-associated tubal factor subfertility: Immunogenetic aspects and serological screening. Hum Reprod Update 12: 719-730, 2006.

15. Sellami H, Said-Sadier N, Znazen A, Gdoura R, Ojcius DM and Hammami A: Chlamydia trachomatis infection increases the expression of inflammatory tumorigenic cytokines and chemokines as well as components of the Toll-like receptor and NF- $\kappa$ B pathways in human prostate epithelial cells. Mol Cell Probes 28: $147-154,2014$.

16. King AE, Wheelhouse N, Cameron S, McDonald SE, Lee KF, Entrican G, Critchley HO and Horne AW: Expression of secretory leukocyte protease inhibitor and elafin in human fallopian tube and in an in-vitro model of Chlamydia trachomatis infection. Hum Reprod 24: 679-686, 2009.

17. Derbigny WA, Shobe LR, Kamran JC, Toomey KS and Ofner S Identifying a role for Toll-like receptor 3 in the innate immune response to Chlamydia muridarum infection in murine oviduct epithelial cells. Infect Immun 80: 254-265, 2012.

18. Frazer LC, Darville T, Chandra-Kuntal K, Andrews CW Jr, Zurenski M, Mintus M, AbdelRahman YM, Belland RJ, Ingalls RR and O'Connell CM: Plasmid-cured Chlamydia caviae activates TLR2-dependent signaling and retains virulence in the guinea pig model of genital tract infection. PLoS One 7: e30747, 2012

19. Mascellino MT, Boccia P and Oliva A: Immunopathogenesis in Chlamydia trachomatis infected women. ISRN Obstet Gynecol 2011: 436936, 2011.

20. IARC Working Group on the Evaluation of Carcinogenic Risks to Humans: Human papillomaviruses. IARC Monogr Eval Carcinog Risks Hum 90: 1-636, 2007.

21. Shanmughapriya S, Senthilkumar G, Vinodhini K, Das BC, Vasanthi $\mathrm{N}$ and Natarajaseenivasan K: Viral and bacterial aetiologies of epithelial ovarian cancer. Eur J Clin Microbiol Infect Dis 31: 2311-2317, 2012

22. Idahl A, Lundin E, Jurstrand M, Kumlin U, Elgh F, Ohlson N and Ottander U: Chlamydia trachomatis and Mycoplasma genitalium plasma antibodies in relation to epithelial ovarian tumors. Infect Dis Obstet Gynecol 2011: 824627, 2011

23. Carvalho JP and Carvalho FM: Is Chlamydia-infected tubal fimbria the origin of ovarian cancer? Med Hypotheses 71: 690-693, 2008

24. Kessler M, Zielecki J, Thieck O, Mollenkopf HJ, Fotopoulou C and Meyer TF: Chlamydia trachomatis disturbs epithelial tissue homeostasis in fallopian tubes via paracrine Wnt signaling. Am J Pathol 180: 186-198, 2012.

25. Zügel U and Kaufmann SH: Role of heat shock proteins in protection from and pathogenesis of infectious diseases. Clin Microbiol Rev 12: 19-39, 1999.

26. Pockley AG: Heat shock proteins as regulators of the immune response. Lancet 362: 469-276, 2003
27. Di Felice V, David S, Cappello F, Farina F and Zummo G: Is chlamydial heat shock protein 60 a risk factor for oncogenesis? Cell Mol Life Sci 62: 4-9, 2005.

28. Tsai YP, Yang MH, Huang CH, Chang SY, Chen PM, Liu CJ, Teng SC and Wu KJ: Interaction between HSP60 and beta-catenin promotes metastasis. Carcinogenesis 30: 1049-1057, 2009.

29. Giaginis C, Daskalopoulou SS, Vgenopoulou S, Sfiniadakis I, Kouraklis G and Theocharis SE: Heat Shock Protein-27, -60 and -90 expression in gastric cancer: Association with clinicopathological variables and patient survival. BMC Gastroenterol 9: 14, 2009.

30. Bodzek P, Partyka R and Damasiewicz-Bodzek A: Antibodies against Hsp60 and Hsp65 in the sera of women with ovarian cancer. J Ovarian Res 7: 30, 2014.

31. Lim R, Lappas M, Ahmed N, Permezel M, Quinn MA and Rice GE: 2D-PAGE of ovarian cancer: Analysis of soluble and insoluble fractions using medium-range immobilized $\mathrm{pH}$ gradients. Biochem Biophys Res Commun 406: 408-413, 2011.

32. Tully JG, Taylor-Robinson D, Cole RM and Rose DL: A newly discovered mycoplasma in the human urogenital tract. Lancet 1 : 1288-1291, 1981.

33. Gibson DG, Benders GA, Andrews-Pfannkoch C, Denisova EA, Baden-Tillson H, Zaveri J, Stockwell TB, Brownley A, Thomas DW, Algire MA, et al: Complete chemical synthesis, assembly, and cloning of a Mycoplasma genitalium genome. Science 319: 1215-1220, 2008.

34. Fraser CM, Gocayne JD, White O, Adams MD, Clayton RA, Fleischmann RD, Bult CJ, Kerlavage AR, Sutton G, Kelley JM, et al: The minimal gene complement of Mycoplasma genitalium. Science 270: 397-403, 1995.

35. Manhart LE, Holmes KK, Hughes JP, Houston LS and Totten PA: Mycoplasma genitalium among young adults in the United States: An emerging sexually transmitted infection. Am J Public Health 97: 1118-1125, 2007.

36. Taylor-Robinson D and Jensen JS: Mycoplasma genitalium: From Chrysalis to multicolored butterfly. Clin Microbiol Rev 24: 498-514, 2011.

37. Idahl A, Lundin E, Elgh F, Jurstrand M, Møller JK, Marklund I, Lindgren $\mathrm{P}$ and Ottander U: Chlamydia trachomatis, Mycoplasma genitalium, Neisseria gonorrhoeae, human papillomavirus, and polyomavirus are not detectable in human tissue with epithelial ovarian cancer, borderline tumor, or benign conditions. Am J Obstet Gynecol 202: 71.e1-e6, 2010.

38. Chan PJ, Seraj IM, Kalugdan TH and King A: Prevalence of mycoplasma conserved DNA in malignant ovarian cancer detected using sensitive PCR-ELISA. Gynecol Oncol 63: 258-260, 1996.

39. Quirk JT, Kupinski JM and DiCioccio RA: Detection of mycoplasma ribosomal DNA sequences in ovarian tumors by nested PCR. Gynecol Oncol 83: 560-562, 2001.

40. Namiki K, Goodison S, Porvasnik S, Allan RW, Iczkowski KA, Urbanek C, Reyes L, Sakamoto N and Rosser CJ: Persistent exposure to mycoplasma induces malignant transformation of human prostate cells. PLoS One 4: e6872, 2009.

41. Zhang S, Wear DJ and Lo S: Mycoplasmal infections alter gene expression in cultured human prostatic and cervical epithelial cells. FEMS Immunol Med Microbiol 27: 43-50, 2000.

42. McGowin CL, Popov VL and Pyles RB: Intracellular Mycoplasma genitalium infection of human vaginal and cervical epithelial cells elicits distinct patterns of inflammatory cytokine secretion and provides a possible survival niche against macrophage-mediated killing. BMC Microbiol 9: 139, 2009.

43. Tsai S, Wear DJ, Shih JW and Lo SC: Mycoplasmas and oncogenesis: Persistent infection and multistage malignant transformation. Proc Natl Acad Sci USA 92: 10197-10201, 1995

44. Haggerty CL and Taylor BD: Mycoplasma genitalium: An emerging cause of pelvic inflammatory disease. Infect Dis Obstet Gynecol 2011: 959816, 2011

45. Baczynska A, Funch P, Fedder J, Knudsen HJ, Birkelund S and Christiansen G: Morphology of human Fallopian tubes after infection with Mycoplasma genitalium and Mycoplasma hominis-in vitro organ culture study. Hum Reprod 22: 968-979, 2007.

46. Crum CP, McKeon FD and Xian W: The oviduct and ovarian cancer: Causality, clinical implications, and 'targeted prevention'. Clin Obstet Gynecol 55: 24-35, 2012.

47. McGowin CL, Annan RS, Quayle AJ, Greene SJ, Ma L, Mancuso MM, Adegboye D and Martin DH: Persistent Mycoplasma genitalium infection of human endocervical epithelial cells elicits chronic inflammatory cytokine secretion. Infect Immun 80: 3842-3849, 2012. 
48. McGowin CL, Radtke AL, Abraham K, Martin DH and Herbst-Kralovetz M: Mycoplasma genitalium infection activates cellular host defense and inflammation pathways in a 3-dimensional human endocervical epithelial cell model. J Infect Dis 207: 1857-1868, 2013.

49. Dunne EF, Unger ER, Sternberg M, McQuillan G, Swan DC, Patel SS and Markowitz LE: Prevalence of HPV infection among females in the United States. JAMA 297: 813-819, 2007.

50. Zhao FH, Lewkowitz AK, Hu SY, Chen F, Li LY, Zhang QM, Wu RF, Li CQ, Wei LH, Xu AD, et al: Prevalence of human papillomavirus and cervical intraepithelial neoplasia in China: A pooled analysis of 17 population-based studies. Int J Cancer 131: 2929-2938, 2012.

51. Hong H, He TF, Ni HX, Zhang S and Xu GZ: Prevalence and genotype distribution of HPV infection among women in Ningbo, China. Int J Gynaecol Obstet 131: 96-99, 2015.

52. Chen Q, Xie LX, Qing ZR, Li LJ, Luo ZY, Lin M, Zhang SM, Chen WZ, Lin BZ, Lin QL, et al: Epidemiologic characterization of human papillomavirus infection in rural Chaozhou, eastern Guangdong Province of China. PLoS One 7: e32149, 2012.

53. Wang YY, Li L, Wei S, Peng J, Yuan SX, Xie JS and Liu ZH: Human papillomavirus (HPV) infection in women participating in cervical cancer screening from to 2010 in Shenzhen city, South China. Asian Pac J Cancer Prev 14: 7483-7487, 2013.

54. Sui S, Jiao Z, Niyazi M, S S, Lu P and Qiao YL: Genotype distribution and behavioral risk factor analysis of human papillomavirus infection in Uyghur women. Asian Pac J Cancer Prev 14: 5861-5865, 2013.

55. Muñoz N, Bosch FX, de Sanjosé S, Herrero R, Castellsagué X, Shah KV, Snijders PJ and Meijer CJ; International Agency for Research on Cancer Multicenter Cervical Cancer Study Group: Epidemiologic classification of human papillomavirus types associated with cervical cancer. N Engl J Med 348: 518-527, 2003.

56. Tang KW, Alaei-Mahabadi B, Samuelsson T, Lindh M and Larsson E: The landscape of viral expression and host gene fusion and adaptation in human cancer. Nat Commun 4: 2513 , 2013.

57. Rosa MI, Silva GD, de Azedo Simões PW, Souza MV, Panatto AP, Simon CS, Madeira K and Medeiros LR: The prevalence of human papillomavirus in ovarian cancer: A systematic review. Int J Gynecol Cancer 23: 437-441, 2013.

58. Al-Shabanah OA, Hafez MM, Hassan ZK, Sayed-Ahmed MM, Abozeed WN, Al-Rejaie SS and Alsheikh AA: Human papillomavirus genotyping and integration in ovarian cancer Saudi patients. Virol J 10: 343, 2013.

59. Bilyk OO, Pande NT, Pejovic T and Buchinska LG: The frequency of human papilloma virus types 16,18 in upper genital tract of women at high risk of developing ovarian cancer. Exp Oncol 36: 121-124, 2014

60. Bilyk OO, Pande NT and Buchynska LG: Analysis of p53, p16(INK4a), pRb and Cyclin D1 expression and human papillomavirus in primary ovarian serous carcinomas. Exp Oncol 33 150-156, 2011.

61. Mahmood FM, Kadhim HS and Mousa Al Khuzaee LR: Detection of human papillomavirus-16 e6-oncoprotein in epithelial ovarian tumors samples of iraqi patients. Jundishapur J Microbiol 7: e11945, 2014

62. Ghittoni R, Accardi R, Chiocca S and Tommasino M: Role of human papillomaviruses in carcinogenesis. Ecancermedicalscience 9: 526, 2015.

63. Münger K and Howley PM: Human papillomavirus immortalization and transformation functions. Virus Res 89: 213-228, 2002.

64. Park JW, Nickel KP, Torres AD, Lee D, Lambert PF and Kimple RJ: Human papillomavirus type 16 E7 oncoprotein causes a delay in repair of DNA damage. Radiother Oncol 113 337-344, 2014

65. Honegger A, Schilling D, Bastian S, Sponagel J, Kuryshev V, Sültmann H, Scheffner M, Hoppe-Seyler K and Hoppe-Seyler F: Dependence of intracellular and exosomal microRNAs on viral E6/E7 oncogene expression in HPV-positive tumor cells. PLoS Pathog 11: e1004712, 2015.

66. Gregoire L, Rabah R, Schmelz EM, Munkarah A, Roberts PC and Lancaster WD: Spontaneous malignant transformation of human ovarian surface epithelial cells in vitro. Clin Cancer Res 7: 4280-4287, 2001

67. Yu J, Solano FX Jr and Seethala RR: Bilateral cytomegalovirus (CMV) oophoritis mimicking widely metastatic carcinoma: A case report and review of the literature. Diagn Pathol 2: 50, 2007.
68. Wick W and Platten M: CMV infection and glioma, a highly controversial concept struggling in the clinical arena. Neuro Oncol 16: 332-333, 2014.

69. Richardson AK, Currie MJ, Robinson BA, Morrin H, Phung Y, Pearson JF, Anderson TP, Potter JD and Walker LC: Cytomegalovirus and Epstein-Barr virus in breast cancer. PLoS One 10: e0118989, 2015.

70. Han CP, Tsao YP, Sun CA, Ng HT and Chen SL: Human papillomavirus, cytomegalovirus and herpes simplex virus infections for cervical cancer in Taiwan. Cancer Lett 120: 217-221, 1997.

71. Harkins L, Volk AL, Samanta M, Mikolaenko I, Britt WJ, Bland KI and Cobbs CS: Specific localisation of human cytomegalovirus nucleic acids and proteins in human colorectal cancer. Lancet 360: 1557-1563, 2002

72. Samanta M, Harkins L, Klemm K, Britt WJ and Cobbs CS: High prevalence of human cytomegalovirus in prostatic intraepithelial neoplasia and prostatic carcinoma. J Urol 170: 998-1002, 2003.

73. Michaelis M, Baumgarten P, Mittelbronn M, Driever PH, Doerr HW and Cinatl J Jr: Oncomodulation by human cytomegalovirus: Novel clinical findings open new roads. Med Microbiol Immunol 200: 1-5, 2011

74. Söderberg-Nauclér C and Johnsen JI: Cytomegalovirus in human brain tumors: Role in pathogenesis and potential treatment options. World J Exp Med 5: 1-10, 2015.

75. Bentz GL and Yurochko AD: Human CMV infection of endothelial cells induces an angiogenic response through viral binding to EGF receptor and beta1 and beta3 integrins. Proc Natl Acad Sci USA 105: 5531-5536, 2008.

76. Bishop RK, Valle Oseguera CA and Spencer JV: Human cytomegalovirus interleukin-10 promotes proliferation and migration of MCF-7 breast cancer cells. Cancer Cell Microenviron 2: pii: e678, 2015.

77. Price RL, Song J, Bingmer K, Kim TH, Yi JY, Nowicki MO, Mo X, Hollon T, Murnan E, Alvarez-Breckenridge C, et al: Cytomegalovirus contributes to glioblastoma in the context of tumor suppressor mutations. Cancer Res 73: 3441-3450, 2013.

78. Scrivo R, Vasile M, Bartosiewicz I and Valesini G: Inflammation as 'common soil' of the multifactorial diseases. Autoimmun Rev 10: 369-374, 2011

79. Karin M, Lawrence $T$ and Nizet V: Innate immunity gone awry: Linking microbial infections to chronic inflammation and cancer. Cell 124: 823-835, 2006.

80. Whiteside TL: The role of immune cells in the tumor microenvironment. Cancer Treat Res 130: 103-124, 2006.

81. Coussens LM and Werb Z: Inflammation and cancer. Nature 420: 860-867, 2002.

82. Mantovani A, Allavena P, Sica A and Balkwill F: Cancer-related inflammation. Nature 454: 436-444, 2008.

83. Enzler T, Gillessen S, Manis JP, Ferguson D, Fleming J, Alt FW, Mihm M and Dranoff G: Deficiencies of GM-CSF and interferon gamma link inflammation and cancer. J Exp Med 197: 1213-1219, 2003.

84. Macciò A and Madeddu C: Inflammation and ovarian cancer. Cytokine 58: 133-147, 2012.

85. Curiel TJ, Coukos G, Zou L, Alvarez X, Cheng P, Mottram P, Evdemon-Hogan M, Conejo-Garcia JR, Zhang L, Burow M, et al: Specific recruitment of regulatory T cells in ovarian carcinoma fosters immune privilege and predicts reduced survival. Nat Med 10: 942-949, 2004.

86. Block MS, Charbonneau B, Vierkant RA, Fogarty Z, Bamlet WR, Pharoah PD; Georgia Chenevix-Trench; for AOCS; /ACS Group, Rossing MA, Cramer D, Pearce CL, et al: Variation in NF- $\kappa \mathrm{B}$ signaling pathways and survival in invasive epithelial ovarian cancer. Cancer Epidemiol Biomarkers Prev 23: 1421-1427, 2014.

87. Trabert B, Ness RB, Lo-Ciganic WH, Murphy MA, Goode EL, Poole EM, Brinton LA, Webb PM, Nagle CM, Jordan SJ, et al: Aspirin, nonaspirin nonsteroidal anti-inflammatory drug, and acetaminophen use and risk of invasive epithelial ovarian cancer: A pooled analysis in the Ovarian Cancer Association Consortium. J Natl Cancer Inst 106: djt431, 2014.

88. Hu T, Li LF, Shen J, Zhang L and Cho CH: Chronic inflammation and colorectal cancer: The role of vascular endothelial growth factor. Curr Pharm Des 21: 2960-2967, 2015.

89. Ellis LM and Hicklin DJ: VEGF-targeted therapy: mechanisms of anti-tumour activity. Nat Rev Cancer 8: 579-591, 2008.

90. Noort AR, van Zoest KP, Weijers EM, Koolwijk P, Maracle CX, Novack DV, Siemerink MJ, Schlingemann RO, Tak PP and Tas SW: NF- $\mathrm{kB}$-inducing kinase is a key regulator of inflammation-induced and tumour-associated angiogenesis. J Pathol 234: 375-385, 2014. 
91. De Spiegelaere W, Cornillie P, Casteleyn C, Burvenich C and Van den Broeck W: Detection of hypoxia inducible factors and angiogenic growth factors during foetal endochondral and intramembranous ossification. Anat Histol Embryol 39: 376-384, 2010

92. Yang Y, Sun M, Wang L and Jiao B: HIFs, angiogenesis, and cancer. J Cell Biochem 114: 967-974, 2013

93. Sherer DM, Eliakim R and Abulafia O: The role of angiogenesis in the accumulation of peritoneal fluid in benign conditions and the development of malignant ascites in the female. Gynecol Obstet Invest 50: 217-224, 2000.

94. Li J, Li S, Chen R, Yu H and Lu X: The prognostic significance of anti-angiogenesis therapy in ovarian cancer: A meta-analysis. J Ovarian Res 8: 54, 2015

95.Jayson GC, Kohn EC, Kitchener HC and Ledermann JA: Ovarian cancer. Lancet 384: 1376-1388, 2014

96. Li G, He L, Zhang E, Shi J, Zhang Q, Le AD, Zhou K and Tang X Overexpression of human papillomavirus (HPV) type 16 oncoproteins promotes angiogenesis via enhancing HIF-1 $\alpha$ and VEGF expression in non-small cell lungcancer cells. Cancer Lett 311: 160-170, 2011

97. Matlaf LA, Harkins LE, Bezrookove V, Cobbs CS and Soroceanu L: Cytomegalovirus pp71 protein is expressed in human glioblastoma and promotes pro-angiogenic signaling by activation of stem cell factor. PLoS One 8: e68176, 2013.

98. Barriere G, Fici P, Gallerani G, Fabbri F and Rigaud M: Epithelial mesenchymal transition: A double-edged sword. Clin Trans Med 4: 14, 2015.

99. Thiery JP, Acloque H, Huang RY and Nieto MA: Epithelialmesenchymal transitions in development and disease. Cell 139: 871-890, 2009.

100. Wang YL, Zhao XM, Shuai ZF, Li CY, Bai QY, Yu XW and Wen QT: Snail promotes epithelial-mesenchymal transition and invasiveness in human ovarian cancer cells. Int J Clin Exp Med 8: 7388-7393, 2015

101. Wu J, Liu Z, Shao C, Gong Y, Hernando E, Lee P, Narita M, Muller W, Liu J and Wei JJ: HMGA2 overexpression-induced ovarian surface epithelial transformation is mediated through regulation of EMT genes. Cancer Res 71: 349-359, 2011.

102. Haslehurst AM, Koti M, Dharsee M, Nuin P, Evans K, Geraci J, Childs T, Chen J, Li J, Weberpals J, et al: EMT transcription factors snail and slug directly contribute to cisplatin resistance in ovarian cancer. BMC Cancer 12: 91, 2012.

103. Cohen EN, Gao H, Anfossi S, Mego M, Reddy NG, Debeb B, Giordano A, Tin S, Wu Q, Garza RJ, et al: Inflammation mediated metastasis: Immune induced epithelial-to-mesenchymal transition in inflammatory breast cancer cells. PLoS One 10 e0132710, 2015 .

104. Choi YJ, Kim N, Chang H, Lee HS, Park SM, Park JH, Shin CM, Kim JM, Kim JS, Lee DH and Jung HC: Helicobacter pylori-induced epithelial-mesenchymal transition, a potential role of gastric cancer initiation and an emergence of stem cells. Carcinogenesis 36: 553-563, 2015

105. Chandrakesan P, Roy B, Jakkula LU, Ahmed I, Ramamoorthy P, Tawifik O, Papineni R, Houchen C, Anant S and Umar S: Utility of a bacterial infection model to study epithelial-mesenchymal transition, mesenchymal-epithelial transition or tumorigenesis. Oncogene 33: 2639-2654, 2014.

106. Duan H, Qu L and Shou C: Mycoplasma hyorhinis induces epithelial-mesenchymal transition in gastric cancer cell MGC803 via TLR4-NF-кB signaling. Cancer Lett 354: 447-454, 2014.

107. Wang L, Tian WD, Xu X, Nie B, Lu J, Liu X, Zhang B, Dong Q, Sunwoo JB, Li G and Li XP: Epstein-Barr virus nuclear antigen 1 (EBNA1) protein induction of epithelial-mesenchymal transition in nasopharyngeal carcinoma cells. Cancer 120 363-372, 2014.

108. Bose SK, Meyer K, Di Bisceglie AM, Ray RB and Ray R: Hepatitis $\mathrm{C}$ virus induces epithelial-mesenchymal transition in primary human hepatocytes. J Virol 86: 13621-13628, 2012.

109. Li H, Li Y, Liu D and Liu J: LPS promotes epithelial-mesenchymal transition and activation of TLR4/JNK signaling. Tumour Biol 35: 10429-10435, 2014.

110.Zhao L, Yang R, Cheng L, Wang M, Jiang Y and Wang S: LPS-induced epithelial-mesenchymal transition of intrahepatic biliary epithelial cells. J Surg Res 171: 819-825, 2011

111. Kondo Y, Higa-Nakamine S, Noguchi N, Maeda N, Toku S, Isohama Y, Sugahara K, Kukita I and Yamamoto H: Induction of epithelial-mesenchymal transition by flagellin in cultured lung epithelial cells. Am J Physiol Lung Cell Mol Physiol 303: L1057-L1069, 2012
112. Franchi L, Park JH, Shaw MH, Marina-Garcia N, Chen G, Kim YG and Núñez G: Intracellular NOD-like receptors in innate immunity, infection and disease. Cell Microbiol 10: 1-38, 2008.

113. Park GB, Kim D, Kim YS, Kim S, Lee HK, Yang JW and Hur DY: The Epstein-Barr virus causes epithelial-mesenchymal transition in human corneal epithelial cells via Syk/src and $\mathrm{Akt} /$ Erk signaling pathways. Invest Ophthalmol Vis Sci 55: 1770-1779, 2014

114. Horikawa T, Yang J, Kondo S, Yoshizaki T, Joab I, Furukawa M and Pagano JS: Twist and epithelial-mesenchymal transition are induced by the EBV oncoprotein latent membrane protein 1 and are associated with metastatic nasopharyngeal carcinoma. Cancer Res 67: 1970-1978, 2007.

115. Sides MD, Klingsberg RC, Shan B, Gordon KA, Nguyen HT, Lin Z, Takahashi T, Flemington EK and Lasky JA: The Epstein-Barr virus latent membrane protein 1 and transforming growth factor- $\beta 1$ synergistically induce epithelial-mesenchymal transition in lung epithelial cells. Am J Respir Cell Mol Biol 44: $852-862,2011$

116. Li T, Li D, Cheng L, Wu H, Gao Z, Liu Z, Jiang W, Gao YH, Tian F, Zhao L and Wang S: Epithelial-mesenchymal transition induced by hepatitis $\mathrm{C}$ virus core protein in cholangiocarcinoma. Ann Surg Oncol 17: 1937-1944, 2010

117. Bapat SA, Mali AM, Koppikar CB and Kurrey NK: Stem and progenitor-like cells contribute to the aggressive behavior of human epithelial ovarian cancer. Cancer Res 65: 3025-3029, 2005.

118. Garson K and Vanderhyden BC: Epithelial ovarian cancer stem cells: Underlying complexity of a simple paradigm. Reproduction 149: R59-R70, 2015.

119. Korkaya H, Liu S and Wicha MS: Regulation of cancer stem cells by cytokine networks: Attacking cancer's inflammatory roots. Clin Cancer Res 17: 6125-6129, 2011.

120. Leizer AL, Alvero AB, Fu HH, Holmberg JC, Cheng YC, Silasi DA, Rutherford T and Mor G: Regulation of inflammation by the NF- $\kappa$ B pathway in ovarian cancer stem cells. Am J Reprod Immunol 65: 438-447, 2011

121. Chefetz I, Alvero AB, Holmberg JC, Lebowitz N, Craveiro V, Yang-Hartwich Y, Yin G, Squillace L, Gurrea Soteras M, Aldo P and Mor G: TLR2 enhances ovarian cancer stem cell self-renewal and promotes tumor repair and recurrence. Cell Cycle 12: 511-521, 2013.

122. Xiang T, Long H, He L, Han X, Lin K, Liang Z, Zhuo W, Xie R and Zhu B: Interleukin-17 produced by tumor microenvironment promotes self-renewal of $\mathrm{CD}_{133^{+}}$cancer stem-like cells in ovarian cancer. Oncogene 34: 165-176, 2015.

123. Castells M, Milhas D, Gandy C, Thibault B, Rafii A, Delord JP and Couderc B: Microenvironment mesenchymal cells protect ovarian cancer cell lines from apoptosis by inhibiting XIAP inactivation. Cell Death Dis 4: e887, 2013.

124. Farina A, Cirone M, York M, Lenna S, Padilla C, McLaughlin S, Faggioni A, Lafyatis R, Trojanowska $M$ and Farina GA: Epstein-Barr virus infection induces aberrant TLR activation pathway and fibroblast-myofibroblast conversion in scleroderma. J Invest Dermatol 134: 954-964, 2014.

125. He Z, Gao Y, Deng Y, Li W, Chen Y, Xing S, Zhao X, Ding J and Wang $X$ : Lipopolysaccharide induces lung fibroblast proliferation through Toll-like receptor 4 signaling and the phosphoinositide3-kinase-Akt pathway. PLoS One 7: e35926, 2012.

126. Erez N, Glanz S, Raz Y, Avivi C and Barshack I: Cancer associated fibroblasts express pro-inflammatory factors in human breast and ovarian tumors. Biochem Biophys Res Commun 437: 397-402, 2013

127. Yeung TL, Leung CS, Wong KK, Samimi G, Thompson MS, Liu J, Zaid TM, Ghosh S, Birrer MJ and Mok SC: TGF- $\beta$ modulates ovarian cancer invasion by upregulating CAF-derived versican in the tumor microenvironment. Cancer Res 73: 5016-5028, 2013.

128. Dimanche-Boitrel MT, Vakaet L Jr, Pujuguet P, Chauffert B, Martin MS, Hammann A, Van Roy F, Mareel M and Martin F: In vivo and in vitro invasiveness of a rat colon-cancer cell line maintaining E-cadherin expression: An enhancing role of tumor-associated myofibroblasts. Int J Cancer 56: 512-521, 1994.

129. Boire A, Covic L, Agarwal A, Jacques S, Sherifi S and Kuliopulos A: PAR1 is a matrix metalloprotease-1 receptor that promotes invasion and tumorigenesis of breast cancer cells. Cell 120: 303-313, 2005 